\title{
The Challenges of Conducting Interdisciplinary Research in Traditional Doctoral Programs
}

\author{
Chris M. Golde* and Hanna Alix Gallagher
}

Department of Educational Administration, University of Wisconsin, 1025 W. Johnson Street, Madison, Wisconsin 53706, USA

Key words: interdisciplinary research; doctoral programs; educational reform.

Graduate education should prepare students for an increasingly interdisciplinary, collaborative, and global job market and should not be viewed only as a byproduct of immersion in an intensive research experience. ...What is needed is not additional specialization. We need a graduate system that is well tuned to the central feature of contemporary life: continuous change. Our objective, therefore, is a breadth of experience so that graduates can keep career options open and have the capacity to switch career tracks both at the beginning of and throughout their professional lives (Committee on Science Engineering and Public Policy 1995, report brief p. 1, full report p. 83, emphasis added).

Consider the American system of doctoral education. By most measures, it is a resounding success; indeed, it is generally considered the world leader in $\mathrm{Ph} . D$. production. Annually over 40,000 Ph.D.s are granted by over 350 universities in hundreds of disciplines to an ever more diverse group of students (National Research Council 1996). Despite its obvious successes, American doctoral education has come under criticism. One prominent and persistent critique is that American doctoral education trains students too narrowly in a subspecialty, leaving new degree holders unprepared to conduct interdisciplinary work (e.g., Panel on Alternate Approaches to Graduate Education 1973; Boyer 1990; Committee on Science Engineering and Public Policy 1995). Most prominently, the National Academy of Sciences' Committee on Science Engineering and Pub-

Received 4 February 1999; accepted 22 March 1999.

*Corresponding author. e-mail. cmonde@facstaff wiscedu lic Policy (COSEPUP) issued a report entitled "Reshaping the graduate education of scientists and engineers." As the quote above suggests, the authors strongly argue that doctoral science students should be trained to engage in interdisciplinary thinking and practice. In particular, leaders of business and industry have emphasized the need for new Ph.D.-holders to be able to work in interdisciplinary settings and on interdisciplinary research teams. Unfortunately, the dominant structures within universities for research and doctoral education make it difficult to conduct interdisciplinary research.

Most research is conducted within the established boundaries of a given discipline, such as molecular biology or organic chemistry. In describing research that crosses disciplinary boundaries, two terms, ,'multidisciplinary" and "interdisciplinary" are generally used. In multidisciplinary research, people bring separate theories, skills, data, and ideas to bear on a common problem. Interdisciplinary research involves bringing together people and ideas from different disciplines to jointly frame a problem, agree on a methodological approach, and analyze the data. Both interdisciplinary and rriultidisciplinary research are based on the traditional disciplines, but interdisciplinary research also involves some sort of "synthesis or integration" (Newell 1984, p. 126). These are not mutually exclusive categories; rather they are two points on a continuum that define ways to conceptualize and conduct research.

Several mechanisms to foster multi- and interdisciplinary research have been created within universities. Some faculty members and their students 
conduct interdisciplinary research from within traditional disciplines. Evidence for the success of much of this work lies in the development and institutionalization (in the form of academic departments) of new disciplines, such as neurosciences, computer science, and materials science. A number of interdisciplinary degree programs have been created at the undergraduate, master's and, to a lesser extent, doctoral level (Fallon 1978; Hellweg and Churchman 1979; Masten 1979; Lange 1984; Miller and McCartan 1990). Many of these programs are in environmental fields (Perrine 1982; Bryant and others 1987; Christensen 1987). Interdisciplinary research centers, such as the federally-funded Engineering Research Centers, provide another mechanism to connect researchers with common interests.

In spite of these opportunities, we believe that only a few students are pursuing interdisciplinary research because the current system of doctoral science education has evolved in a way that strongly encourages specialization, and consequently, is inhospitable to interdisciplinary scholarship. In this article, we examine the challenges facing doctoral science students in traditional programs who desire to undertake interdisciplinary work. We are not scientists; instead we make our arguments based on several years of study of American doctoral education and the experiences of science doctoral students.

\section{THE STRUCTURE OF SCIENCE DOCTORAL EDUCATION}

The $\mathrm{Ph} . \mathrm{D}$. is a research degree, designed to prepare students to become scholars. At the conclusion of the degree program, "the student should have acquired the knowledge and skills expected of a scholar who has made an original contribution to the field and has attained the necessary expertise to continue to do so" (Council of Graduate Schools 1990, p. 1). Three interconnected features at the core of the contemporary American science doctoral education system have evolved together to push students into specialized disciplinary research.

First, academic departments-local manifestations of a discipline-are the primary locus of control for doctoral education. Departments have almost complete control and discretion to set admissions criteria, administer financial support, determine the curriculum, and set the standards for the various requirements that students must complete (exams, proposals, and dissertations). Because departments are designed to foster knowledge within their discipline, and their reputation and resources flow from recognition within the field, it is in the department's interest to foster research that will garner accolades from within the field. This bias towards disciplinary, rather than interdisciplinary, research is expressed in departmental policies. For example, dissertation committee members may be required to come primarily from within the department.

Second, students work for and with individual faculty members who can exercise enormous power over students' studies. The most important of these mentors is the advisor, who not only helps students design a course of study but also directs their research. In most of the physical and life science disciplines, students routinely become part of their advisor's research team and build their individual research on work done in the advisor's lab or group. The advisor's earlier research usually provides the intellectual foundation for the dissertation. As a result, a student has strong incentives to follow the research direction set by the advisor, typically located within the mainstream of the discipline. Furthermore, the advisor is often the sole arbiter of whether students have completed sufficient quality work to merit receipt of the degree. Consequently, the advisor can wield enormous control over many aspects of a student's professional life. The recent suicide of Jason Altom, at the time a doctoral student in the Harvard Chemistry department, and the issues he raised in his suicide note, provide dramatic evidence of this point (Hall 1998).

Last, further ties between advisors and students are created by the mechanisms that provide funding for research. Since WWII, the federal government has deliberately located most federally-funded research inside of universities [rather than in independent labs, as is the case in many other countries (Geiger 1990; Gumport 1993)] through research grants awarded to individual faculty members, who in turn use this money to fund their students' tuition and research expenses.

\section{CHALLENGES TO STUDENT-CONDUCTED INTERDISCIPLINARY RESEARCH}

As this brief overview of science doctoral education suggests, the current structure ties students to a home department, discipline, and advisor, thus encouraging disciplinary specialization. This system discourages interdisciplinary research by doctoral scientists. To illustrate this contention, we generated a list of four challenges that are likely to be faced by a student who begins a doctoral program intending to pursue interdisciplinary research. While we list these as separate problems, we see them as interconnected, a point we return to later. Keep in mind that 
interdisciplinary research can take place between disciplines that are quite close together-chemistry and biochemistry-or disciplines that are dissimilar and distant-sociology and zoology. The challenges of the latter are much greater and as a result each of these obstacles might be more or less problematic for a given student.

\section{Finding an Advisor}

The ideal dissertation advisor is supportive, experienced, supplies resources, and socializes the student into the discipline. Choosing an advisor with whom the student can build a supportive professional relationship is perhaps the most critical decision a student makes. In many respects, the student is shaped and changed by the advisor: learning how to identify and think through a problem, how to conduct high-quality research, how to write manuscripts and where to publish them, and so forth. For a student with interdisciplinary interests, a good advisor also needs to understand and share the student's commitment to interdisciplinary research. Identifying such an advisor may not be easy.

Interdisciplinary research by students is easiest when the advisor conducts such research him- or herself. However, relatively few faculty conduct interdisciplinary research, although this is impossible to quantify. Some faculty fear the negative consequences of taking up interdisciplinary topics, such as difficulty obtaining tenure, research funding, or peer recognition. This has been identified as a particularly acute problem for untenured faculty (Gumport 1988; Heberlein 1988).

For a student who attempts to conduct investigations outside or beyond the advisor's expertise, additional problems emerge. The advisor may be unable to help the student identify relevant literature and resources. The advisor is likely to be hard-pressed to assist the student in minimizing false starts on research ideas. Relatedly, the student might face the additional hurdle of finding a supportive dissertation committee; faculty from the home department may not support the work, and those in other departments are difficult to identify.

\section{Mastering Knowledge and Reconciling Conflicting Methodologies}

As the amount of knowledge in any field continues to increase dramatically, students must master increasing amounts of information and increasingly specialized techniques-breadth is of necessity sacrificed for depth, producing ever-more specialized researchers. This makes it difficult for students to acquire a sufficiently solid base of knowledge in their own discipline, much less another field, to make significant research contributions.

Students with interdisciplinary interests can either attempt to gain knowledge in more than one field or they can collaborate with a researcher outside of their home discipline. Most, of course, do a combination of both, each of which has particular challenges. A student seeking to gain an understanding of multiple disciplines must struggle to master relevant knowledge from each field. It is not enough, however, to recommend that students take basic courses in other fields because they might not even cover topics that cross their interdisciplinary interests in a meaningful way. To illustrate, a chemist working in a neurosciences lab recently told us, "I cannot understand my colleagues' presentations at a level that makes my input useful for the overall goals of the lab. The learning curve is steep, and I simply cannot do all of the reading to get more than cursory knowledge of my labmates' specialties."

on the other hand, the student who chooses to collaborate faces the time and emotional strains associated with working with others. Successful collaboration requires power sharing and building trusting interpersonal relationships (Whyte 1978; Heberlein 1988; Wood and Gray 1991; Hafernik and others 1997). Although some maintain that this process is more fulfilling and produces a better end product, experienced researchers cite difficulties in finding partners, coordinating multiple schedules, and negotiating issues such as authorship (Heberlein 1988; Hafernik and others 1997). Furthermore, incorporating collaborative research into a dissertation is only acceptable in some fields. (In the humanities and many social sciences solo-authored single works are the standard; a dissertation comprising multiple coauthored papers, as in the sciences, would not be tolerated.) in short, the path to becoming fluent in two or more disciplines is unclear and certainly requires additional time. Environmental scientists would argue that the inherently interdisciplinary nature of ecological research makes collaborative skills especially critical for success. Therefore, graduate programs in these fields need to be especially careful that students obtain experience collaborating.

Beyond mastering the concepts and language of another discipline, working in the interstices of two disciplines means conceptualizing and undertaking research in the absence of established and proven frameworks and models. Trying to integrate two disciplines often means resolving conflicts between research paradigms and methods. The research paradigms in different fields (and within some fields) are predicated on different assumptions about what 
constitutes evidence, what standards of proof are, and what passes for "truth" in the discipline (Heberlein 1988; Laslett 1990). For example, a wellselected and rigorously constructed case study relying on extensive interview data is seen as a valuable contribution to theory and practice in sociology but is often dismissed in physical science as "anecdotal" and unable to be replicated (Miller and McCartan 1990).

\section{Finding an Intellectual Community}

An intellectual community provides valuable socialization and helps contribute to student success (Baird 1990; Tinto 1993). Students need to find faculty to provide intellectual input and fellow students to provide collegiality, emotional support, and a safe arena for formulating and honing new ideas. Working in a nontraditional or emerging field, however, makes it more difficult to develop this type of community. Often the people who would be natural colleagues and collaborators are in several different departments. It is often hard to learn the expertise and interest of scholars who are physically and organizationally distant. This is a particularly challenging obstacle for students to surmount, as there are few mechanisms connecting them to faculty or students in other departments. An interdisciplinary student is vulnerable to feeling intellectually homeless, without a place to share interests and long-term goals.

\section{Overcoming Fears}

Graduate students often believe themselves to be significantly dependent on faculty, and perceive their options to be restricted. Consequently, students often act fearfully and avoid taking risks, and, indeed, the stakes are often very high (Hahn 1984). One fear expressed by students interested in pursuing interdisciplinary research is that their work may have few outlets for publication, and the rewards for such publications are minimal (Heberlein 1988; Hafernik and others 1997). Colleagues may not value publications in journals outside of the home discipline, which aggravates students' fears about having their work recognized and ultimately becoming employed.

Another concern is that the traditional academic job market is now more difficult to enter than in earlier decades, and few signs indicate that this will change. Most positions are located in traditional departments, and students whose work is hard to categorize in traditional ways may be at a disadvantage (Gumport 1990; Miller and McCartan 1990). Thus choosing an interdisciplinary research topic may be intellectually appealing but not strategic or viable. Of course not all students aspire to careers within academia; many look to industry and government, from which many of the calls for students with interdisciplinary skills emanate. Still, it is difficult to forecast the demand for employees in any field five to ten years in advance-the time line relevant for new graduate students.

\section{CONCLUSION}

These four challenges should not be considered a checklist of problems, but rather a linked set of issues faced by students to greater or lesser degrees depending on their interests and situations. These challenges are connected: a student working with an advisor who favors publishing in mainstream disciplinary journals may worry about getting a good reference letter should she strike out in interdisciplinary directions. An advisor who views a student as his employee and intellectual offspring may discourage the student from taking classes in other fields, reducing her opportunities to make intellectual and professional connections in another lab or department. As described earlier, these interconnections spring from the organization of academic departments and the ways that research funding, prestige, and other institutional resources flow to faculty and departments.

These are, however, solvable problems. Tackling them requires holistic solutions and systems thinking. We believe that small changes, such as encouraging students to take courses in other departments, may not foster truly interdisciplinary research, although they surely are a step in the right direction. If it is to nurture interdisciplinary research, graduate education must be "reshaped," not just tweaked around the edges.

One example of a successful effort at nurturing interdisciplinary research is the reorganization of all of the biomedical sciences at Emory University into six interdisciplinary research clusters (such as neurosciences and genetics), instead of more traditional departments. A detailed description of the program and the process of implementation of this change can be found at [http://wcer.wisc.edu/gradedforum]. While the planning and implementation process was time consuming and required political will and considerable resources, it has resulted in programs that attract high-quality students, have high completion rates, and are highly regarded in the research community. Another example, from ecology, is the Environmental Science and Engineering program at UCLA that has granted doctorates to over 170 students since it was founded in 1973. The program draws faculty from over a dozen depart- 
ments including sociology, chemical engineering, environmental health sciences, and economics. Interdisciplinary research is fostered both in "problems" courses that provide a collaborative applied research opportunity and an internship in the field. In both cases, the programs faced significant challenges stemming from the organizational norms of their respective universities (Perrine 1982).

In this commentary, we contend that our system of graduate education has evolved into a form that nurtures disciplinary specialization and is inherently inhospitable to interdisciplinary work. By understanding that graduate education is a complex and interconnected system that inherently favors traditional disciplinary research, we can understand why decades of calls for change have yet to yield a form of doctoral education that nurtures interdisciplinary research on a widespread basis. Some modest efforts-measured by the number of students affected-such as interdisciplinary programs, interdisciplinary departments, and interdisciplinary research funding have been initiated. But, we do not expect a dramatic increase in the interdisciplinary training gained by doctoral students because, to date, few reform efforts have grappled with the basic goals and structures of doctoral education. This is not intended as a pessimistic lament; we offer this analysis as a necessary step to making thoughtful proposals for change.

\section{ACKNOWLEDGMENTS}

We thank Dean Pribbenow, Helen Golde, Ramona Gunter, Hellmut Golde, Tim Dore, Phil Gallagher, Marcy Golde, Mary Gallagher, and R. Scott Lutz for feedback on earlier versions of this essay.

\section{REFERENCES}

Baird LL. 1990. The melancholy of anatomy: the personal and professional development of graduate and professional school students. In: Smart JC, editor. Higher education: handbook of theory and research. New York: Agathon Press.

Boyer EL. 1990. Scholarship reconsidered: priorities of the professoriate. Princeton, NJ: The Carnegie Foundation for the Advancement of Teaching.

Bryant B, Crowfoot J, Gregerman S, Kaplan R, Nowak P, Stapp W. 1987. Environmental education, advocacy, and communication: School of Natural Resources, The University of Michigan. Environ Professional 9(3):196-201.

Christensen MN. 1987. Energy and natural resources group, University of California, Berkeley. Environ Professional 9(3): 201-3.

Committee on Science Engineering and Public Policy. 1995. Reshaping the graduate education of scientists and engineers. Washington, DC: National Academy Press.
Council of Graduate Schools. 1990. The doctor of philosophy degree. Washington DC: Council of Graduate Schools.

Fallon D. 1978. The new master's degrees. Change 10(9):19-22.

Geiger RL. 1990. Organized research units-their role in the development of university research. J Higher Educ 61(1):1-19.

Gumport PJ. 1988. Curricula as signposts of cultural change. Rev Higher Educ 12 (1):49-61.

Gumport PJ. 1990. Feminist scholarship as a vocation. Higher Educ 20:231-43.

Gumport PJ. 1993. Graduate education and organized research in the United States. In: Clark BR, editor. The research foundations of graduate education: Berkeley: University of California Press. p 225-60.

Hafernik JJ, Messerschmitt DS, Vandrick S. 1997. Collaborative research: why and how? Educ Res December, 31-5.

Hahn J. 1984. Disciplinary professionalism: second view. In: Jones RM, Smith BL, editors. Against the current: reform and experimentation in higher education. Cambridge: Schenkman Publishing. p 19-33.

Hall SS. 1998. November 29. Lethal chemistry at Harvard. The New York Times Magazine: 120-8.

Heberlein TA. 1988. Improving interdisciplinary research: integrating the social and natural sciences. Soc Nat Res 1:5-16.

Hellweg SA, Churchman DA. Maximizing the instructional process: a model for the design of graduate degree programs; 1979 July 1979; Kansas City. p 13.

Lange CJ. 1984. The interdisciplinary Ph.D. program in educational policy. In: Mondal CC, editor. Relevance revisited: curriculum development in the humanities. p 31-3.

Laslett B. 1990. Interdisciplinary teaching and disciplinary reflexes. Historical Methods 23(3):130-2.

Masten LW. 1979. A graduate program in toxicology: administrative and educational benefits of intradepartmental management. Am J Pharm Educ 43 (1):23-6.

Miller MA, McCartan A-M. 1990. Making the case for new interdisciplinary programs. Change 22(3):28-35.

National Research Council. 1996. Summary report 1995. Doctorate recipients from United States universities. Washington, DC: National Academy Press.

Newell WH. 1984. Interdisciplinary curriculum development in the 1970's: the paracollege at St. Olaf and the Western College Program at Miami University. In: Jones RM, Smith BL, editors. Against the current: reform and experimentation in higher education. Cambridge: Schenkman. p 127-47.

Panel on Alternate Approaches to Graduate Education. 1973. Scholarship for society. Princeton, NJ: Educational Testing Service.

Perrine RL. 1982. TSCA and the universities: educating the environmental chemical professional. Environ Professional 4(2): 187-97.

Tinto V. 1993. Appendix B: toward a theory of doctoral persistence. Leaving college: rethinking the causes and cures of student attrition. 2nd ed. Chicago: University of Chicago Press. p 230-43.

Whyte WE 1978. Extradepartmental enterprise. Society 55(3): 22-5.

Wood DJ, Gray B. 1991. Toward a comprehensive theory of collaboration. J Appl Behav Sci 27(2):139-62. 